\title{
EDITORIAL
}

\section{Environmental information and children: the big and the small}

A play at my elder son's school in March told the story of a group of aliens who come to Earth and are disgusted by the littering, the short-sighted chopping down of trees, crude exploitation of wild animals, and profligate use of harmful chemicals and materials, by Earth's environmentally uncanny inhabitants. That story was not entirely new to me: the songs which the children sang had been repeatedly practised in our home for weeks before the event! By the time the parts were performed on the stage of the old church hall, we were able to sing along. This participation added force to my recognition of how strong messages can be conveyed at an early stage in our lives, and how these can hopefully bring on the day more rapidly when practises which are unsound are discontinued. I do not recall such plays when I was of that age, although there was frequent encouragement to learn from the natural world, amongst others through appreciating the form of wind-dispersed seeds, the growth of crystals, or the development of a frog's egg. It seems now that the linkages between dwindling resources, a burgeoning human population and a finite planet are no longer aspects of natural history: they are ever-more immediate and increasingly-urgent pointers to a need for fuller understanding of the human condition in its ecological context.

In 'The Bumblesnouts save the world', the present play performed by 5-8 year olds, the aliens, through sensitive example, stopped the shooting, halted the chopping, brought recycling where there was sheer waste and helped to ban excessive spraying. Earth's people learned to live within their carrying capacity. The Bumblesnouts thus saved the world! Encouraged by the hope that this type of education can bring, it is nevertheless worth asking how effective it will be, and where the message is not heard, what can be done to make it so.

People in comfortable circumstances, like many in that hall, have time to listen to such a message, even though I do wonder whether it will cause them to alter their engrained habits. Which of them will now walk or cycle where they used to drive, or think about environmental impacts when they decide what products to buy? The next generation, my son's class-mates, may do better than their parents, but how much impact can such a child's play have amongst the less fortunate? Even here, in this corner of one of the most prosperous countries on Earth, poverty and social despondency are major issues. I believe that, were I to venture onto the streets of Newcastle upon Tyne to assess people's attitudes to environmental issues, I would be struck by the level of disinterest, or more particularly maybe, by an overriding concern for matters other than 'the environment', such as for the future of jobs, payment of a mortgage or security of a family.

Quite clearly the impact of this small children's play, and other such allegories, on environmental practice in the local population as a whole is far from certain. Simply, the fact that I have the above doubt should alone be a matter for concern. If that is so here, in one part of England, what hope can there be for those corners of the world where a majority of people struggle for their livelihood? While hope abounds in the play, the question remains as to whether the signal is strong enough. The very same media which bring us messages such as that of the Bumblesnouts convey a multitude of other images to those of impressionable age. Judging from the menu to which my own children have access, particularly on television but also elsewhere, I suspect that more forceful to them are the prevalence of personal violence, of endless streets, cars and buildings, and of whole landscapes which are often devoid, it seems, of due consideration for the wider ecological linkages that sustain us. Sometimes, even eating would appear to have been dispensed with!

In many parts of the world sheer struggle for survival is far more intense, and the prospects more daunting still. Education is playing its part there too, but the counter-pressures are overwhelming. Environmental conservation can only seem a rich man's concept to those with little to eat, little to burn, and little land to till. They often know how they would like to use their resources, but are prevented from conserving them by immediacy, lack of tenure for example and downright poverty. It is interesting to speculate that were a Bumblesnout crusade to happen there, it might defend people against outside pressures, for example by re- 
turning land to them, helping them to achieve sustainable economic growth, and shielding them from misleading messages about the superiority of other cultures. Indeed, this sort of thing is happening in some areas.

One challenge for environmentalists is how to turn knowledge more effectively into action when the Earth is so diverse, such that the solutions of Newcastle upon Tyne are not the same as those of Naivasha or Vanuatu. Implicit in this challenge is that the knowledge is of the right kind.'A journal such as this presents science at a level far removed from people on the ground, it is true, but the scientific method is universal. It includes meticulous observation, rigorous analysis, scrutiny of meaning, and application to clearly-defined goals. Environmental Conservation, as I see it then, plays a part in enhancing the application of this method to environmental issues. It constitutes one element, albeit a major one, in a network involving providers of data, disseminators, practitioners, politicians, legislators and people on the ground. It is also hopefully part of an omnidirectional process: not merely a conduit from providers of new information to users of it, but also back again, and repeatedly so, as understanding increases. In that way the universal method is adaptable to local issues whatever their nature and wherever they arise. Children are not obvious participants in the processes involved, but hopefully they are not often far from the minds so engaged, and will ultimately benefit from the process.

Nicholas V.C. Polunin

Editor 